\title{
PLANO DE HOMOLOGAÇÕES DE MOTORES DESENVOLVIDO PELA FPT INDUSTRIAL PARA ATENDER MAR-I
}

\author{
Gustavo Júlio Soares Teixeira, Luiz Augusto de Noronha Mendes, Rafael Silveira Pires, Julio
}

César de Melo, Janderson de Oliveira Menez

FPT Industrial

\begin{abstract}
gustavo.teixeira@cnhind.com, luiz.noronha@cnhind.com, rafael.pires@cnhind.com, julio.melo@cnhind.com, Janderson.menez@cnhind.com
\end{abstract}

\section{RESUMO}

Os fabricantes de motores, veículos rodoviários e máquinas fora-de-estrada devem aprimorar continuamente os seus produtos, de modo a atender aos mais exigentes padrões de desempenho, consumo de combustível e emissões de poluentes. Essas demandas estão diretamente ligadas a pesquisa, desenvolvimento e investimento. O mercado Brasileiro vem vivenciando a evolução contínua do PROCONVE (Programa de Controle da Poluição do Ar por Veículos Automotores), através de grandes reduções de poluentes do ar obtidos com automóveis, caminhões, ônibus e motocicletas, desde meados da década de 80. Agora o desafio é homologar também os tratores, equipamentos de construção e máquinas agrícolas em geral, através do MAR-I (Máquinas Agrícolas e Rodoviárias). FPT Industrial está homologando 49 versões de motores, obtendo redução expressiva na emissão de Material Particulado e Óxidos de Nitrogênio.

\section{PROCONVE}

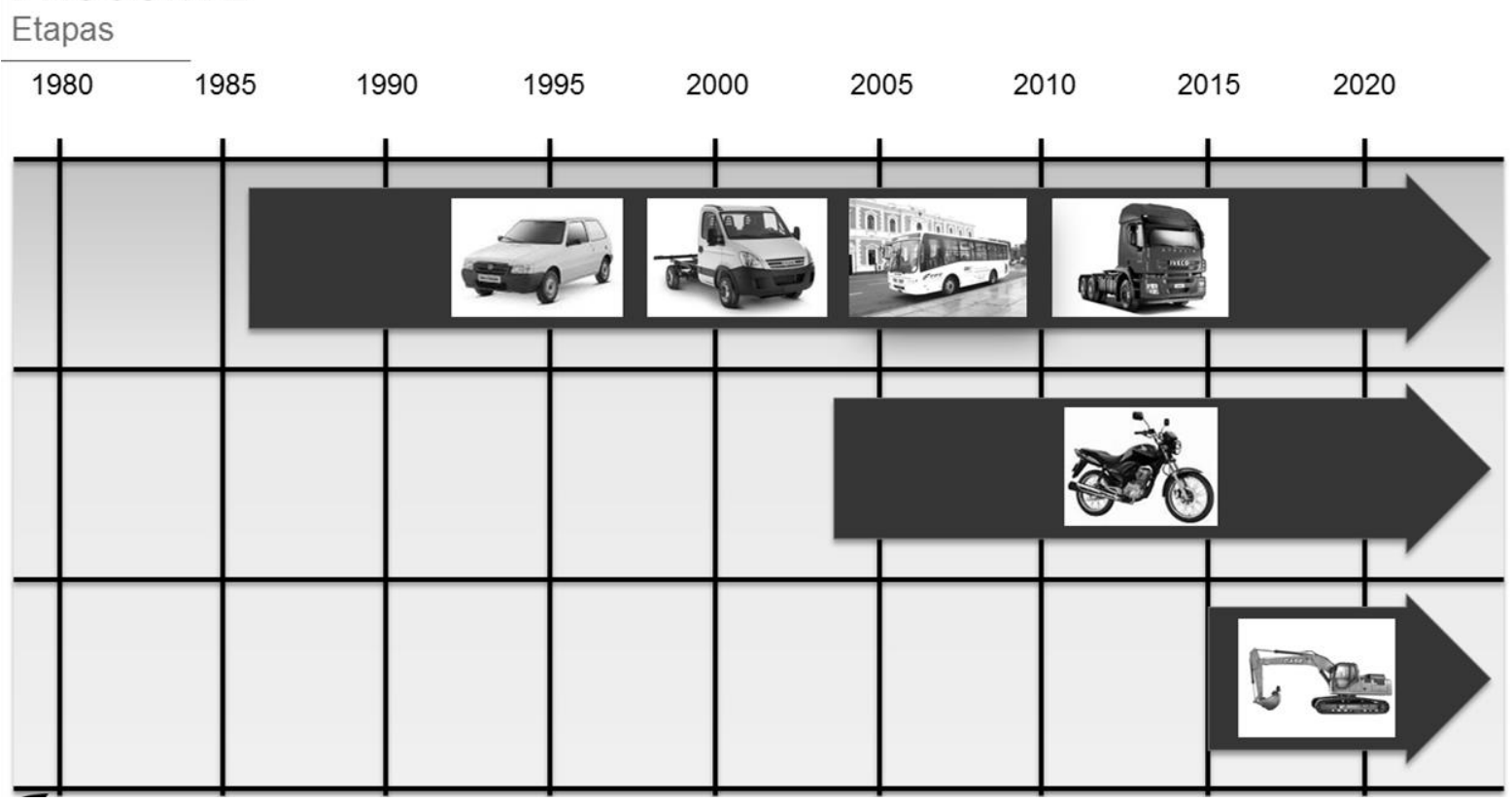

Figura 1: As etapas do PROCONVE 


\section{INTRODUÇÃO}

Os motores de combustão interna estão presentes na grande maioria das atividades do nosso dia-a-dia, seja através do automóvel que utilizamos para pequenos deslocamentos urbanos, seja nos veículos para transporte de passageiros ou mercadorias, geração de energia elétrica, entre outros. Eles são frutos de desenvolvimentos criteriosos, com dezenas de Engenheiros envolvidos, milhares de horas de projeto, testes experimentais, validação e homologação. Grande parte deste trabalho tem como principal objetivo o controle de emissões de gases de escape, que, caso não sejam adequadamente controladas, podem causar sérios danos à nossa saúde e ao meio-ambiente.

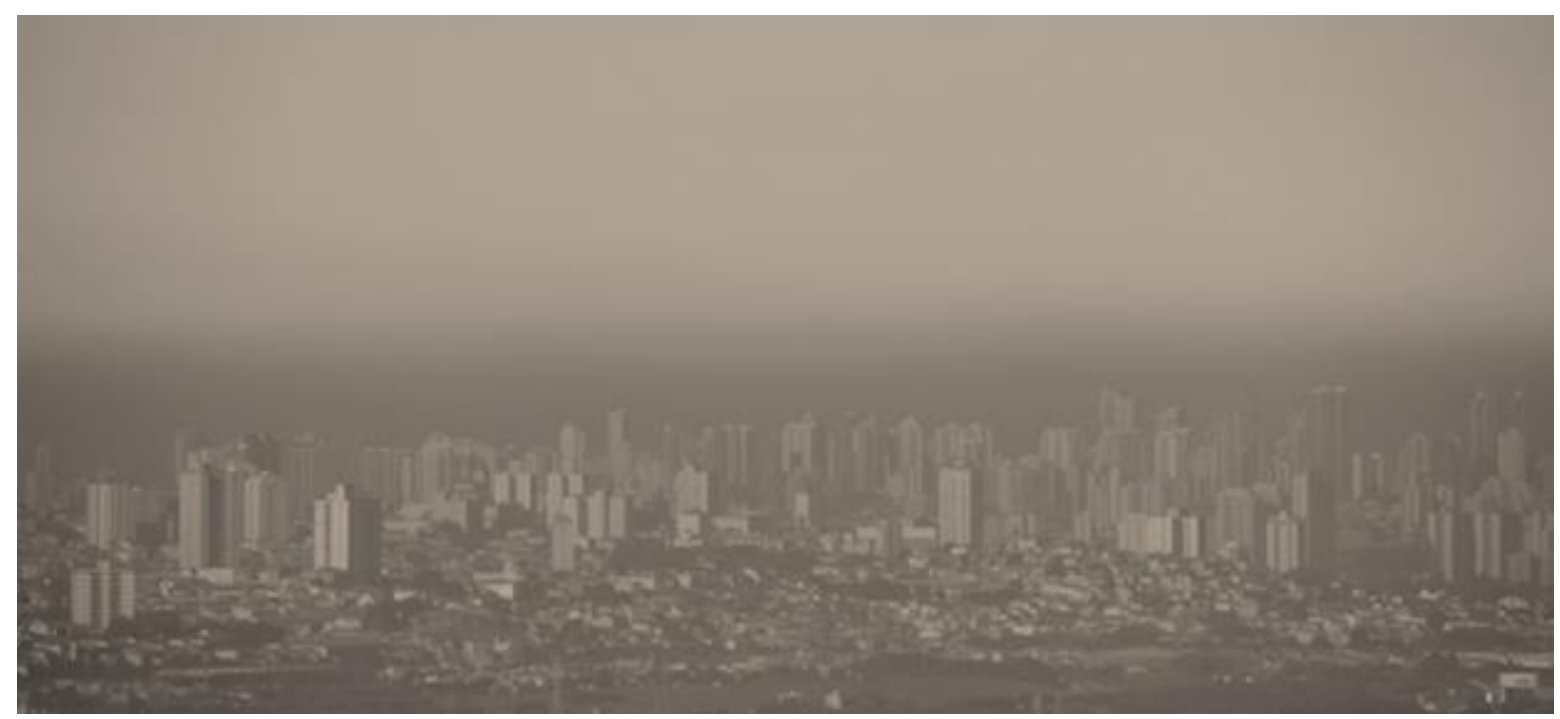

Figura 2 : Emissão de poluentes na Região Metropolitana de São Paulo

\section{EMISSÕES DE GASES DE ESCAPE}

As emissões de gases de escape variam de acordo com cada ciclo de operação do motor (Diesel ou Otto), deslocamento volumétrico, condições de operação, combustível utilizado, entre outros fatores, e os poluentes típicos são:

\subsection{MATERIAL PARTICULADO}

É a massa de sólidos e constituintes voláteis ou solúveis agregados. As partículas são compostas principalmente por Carbono em sua forma elementar. Os compostos orgânicos consistem em Hidrocarbonetos não queimados, provenientes do óleo lubrificante ou combustível. A fração de Sulfatos é basicamente determinada pela presença de Enxofre no 
combustível e óleo do motor. Frações suspensas de Material Particulado podem causar irritação e inflamação nos pontos onde se depositam no corpo humano. Grande parte das partículas é retida no nariz e laringe, enquanto uma pequena fração pode alcançar os brônquios e alvéolos. Partículas ultrafinas, menores que $0,1 \mu \mathrm{m}$ podem atingir a corrente sanguínea através dos alvéolos pulmonares e se espalhar no corpo humano através da corrente sanguínea. Material Particulado pode causar diversas doenças respiratórias, e até mesmo Câncer.

\section{2. ÓXIDOS DE NITROGÊNIO}

Normalmente chamados de NOx, os óxidos de Nitrogênio são formados a partir das altas temperaturas e pressões nos motores de combustão interna. São compostos basicamente por Óxido Nítrico (NO), Óxido Nitroso $\left(\mathrm{N}_{2} \mathrm{O}\right)$ e Dióxido de Nitrogênio $\left(\mathrm{NO}_{2}\right)$, entre outros. São gases que causam grande irritação às membranas e mucosas em geral e podem causar chuva ácida, quando em contato com umidade do ar. Aumentam o risco de Asma e doenças respiratórias em geral. $\mathrm{NO}_{2}$ possui efeito fertilizante sobre as plantas.

\subsection{HIDROCARBONETOS NÃO QUEIMADOS (OU COMPOSTOS ORGÂNICOS VOLÁTEIS)}

Os motores Diesel podem emitir Hidrocarbonetos Não-Queimados (HC) quando quantidades de combustível atingem regiões com temperaturas inadequadas para a combustão. Pontos localizados com mistura muito rica também são considerados outras fontes de emissão de HC. Combustível presente nos orifícios dos injetores após o final da injeção é uma fonte adicional de emissão de HC. Essa parcela de combustível evapora durante a fase de expansão a temperaturas bem abaixo do limite necessário para oxidação e é empurrada para o sistema de exaustão, ainda não queimada. Pode causar irritações nos olhos, garganta e mucosas em geral.

\subsection{MONÓXIDO DE CARBONO}

Trata-se de um gás inodoro, incolor, entre outras características, que pode causar a morte em alguns minutos por asfixia. As emissões de Monóxido de Carbono (CO) em motores Diesel são geralmente muito baixas.

\subsection{DIÓXIDO DE CARBONO}

Gás inerte e inofensivo diretamente à saúde humana, é responsável, juntamente com o Metano $\left(\mathrm{CH}_{4}\right)$ e outros gases pelo Efeito Estufa, que causa o aquecimento global. $\mathrm{CO}_{2}$ é responsável por cerca de $70 \%$ do aumento de temperatura global estimada para os próximos anos.

A redução de emissões de poluentes estabelecida pelo PROCONVE MAR-I (equivalente ao padrão europeu Stage IIIA) representa um importante avanço para o mercado Brasileiro, correspondendo a uma redução de mais de $60 \%$ do Material Particulado e 56\% dos Óxidos de Nitrogênio. 


\begin{tabular}{|c|c|c|c|}
\hline $\begin{array}{c}\text { Potência } \\
(\mathrm{kW})\end{array}$ & co & HC+NOx & MP \\
\hline
\end{tabular}

\begin{tabular}{|c|c|c|c|}
\hline $130 \leq P \leq 560$ & 3.5 & 4.0 & 0.2 \\
\hline $75 \leq P<130$ & 5.0 & 4.0 & 0.3 \\
\hline $37 \leq P<75$ & 5.0 & 4.7 & 0.4 \\
\hline $19 \leq P<37$ & 5.5 & 7.5 & 0.6 \\
\hline
\end{tabular}

Tabela 1: Limites de emissões de poluentes estabelecido pelo PROCONVE MAR-I

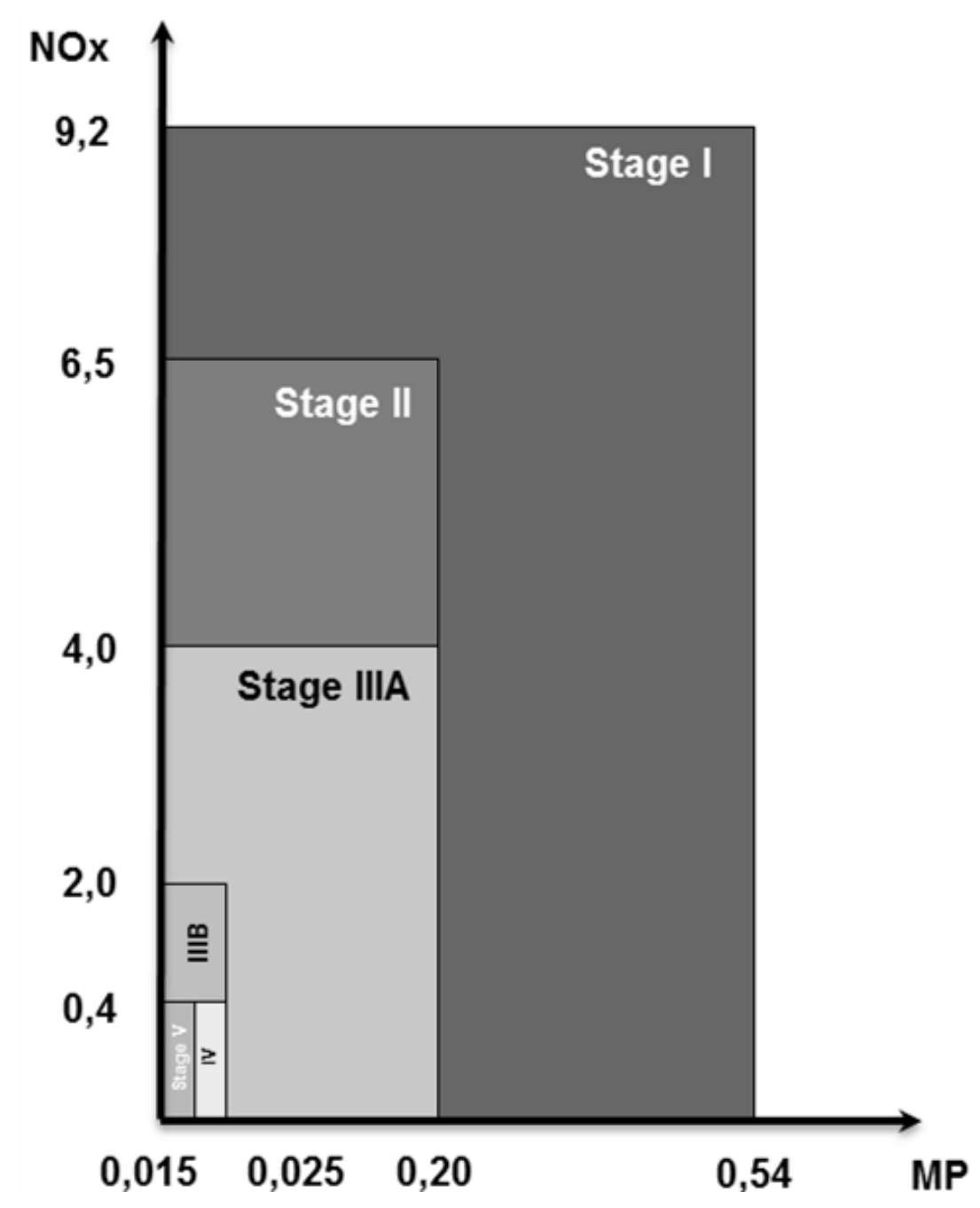

Figura 3: Redução de Emissões de poluentes para máquinas fora-de-estrada na Europa

\section{PROCONVE MAR-I}

O CONAMA, através da resolução 433 de 2011, estabeleceu os limites de emissões a serem cumpridos pelos fabricantes de motores e o calendário de implantação, em diferentes fases, de modo que as empresas pudessem se organizar. 


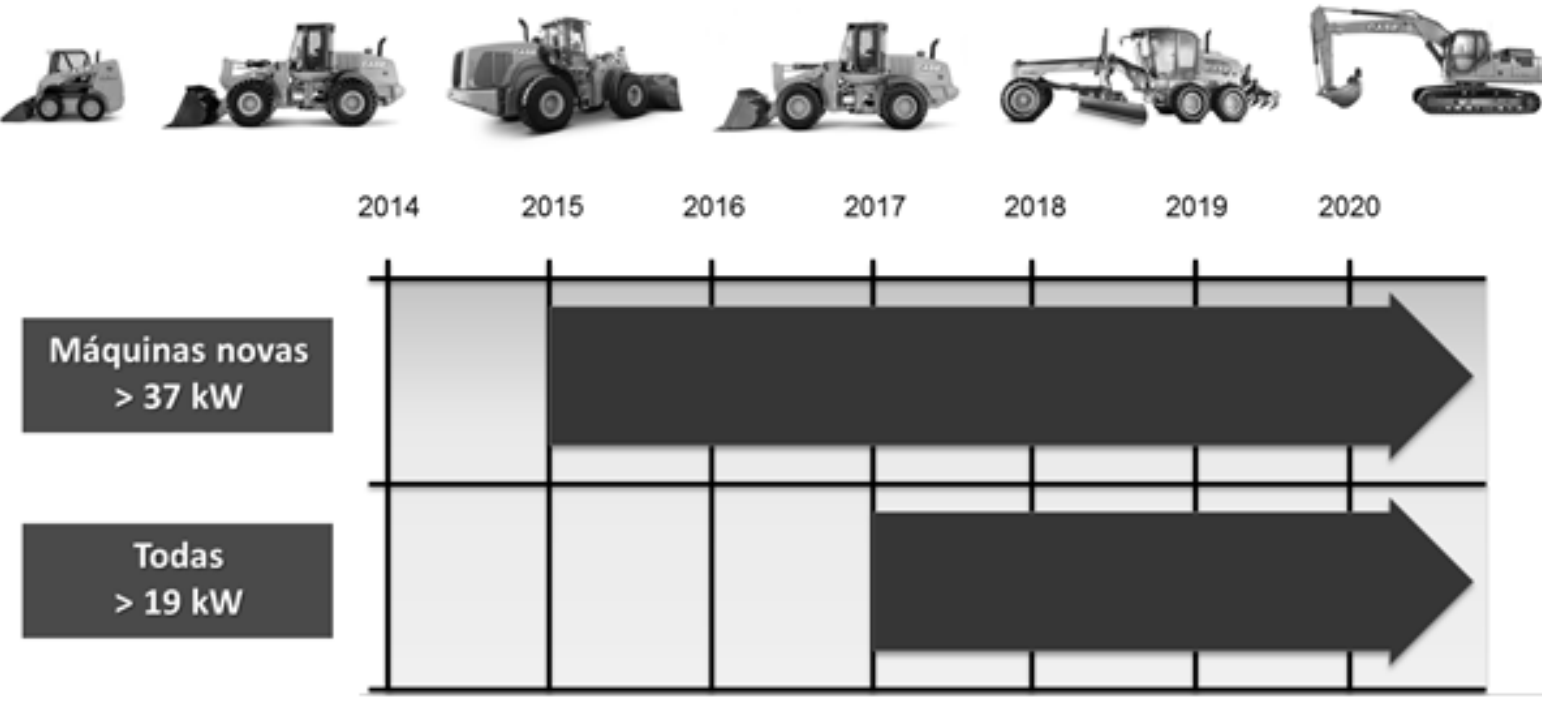

Figura 4: Calendário de implantação do PROCONVE MAR-I para máquinas de Construção

\section{PROCONVE MAR-I}

Tratores e máquinas agrícolas - Gases

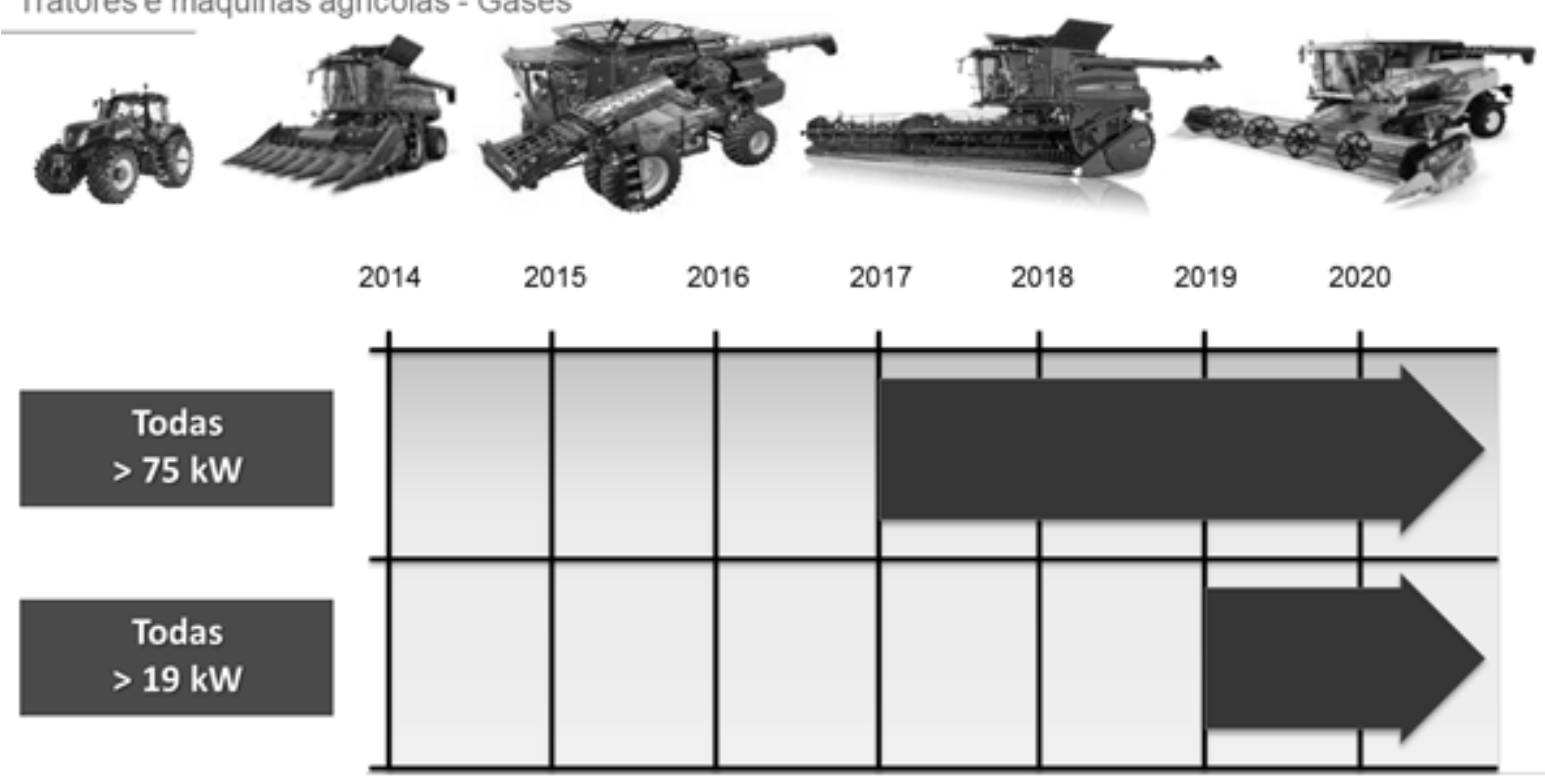

Figura 5: Calendário de implantação do PROCONVE MAR-I para máquinas agrícolas

Através desse importante passo, o Brasil se tornou referência na América Latina para limites de emissões em equipamentos fora-de-estrada. 

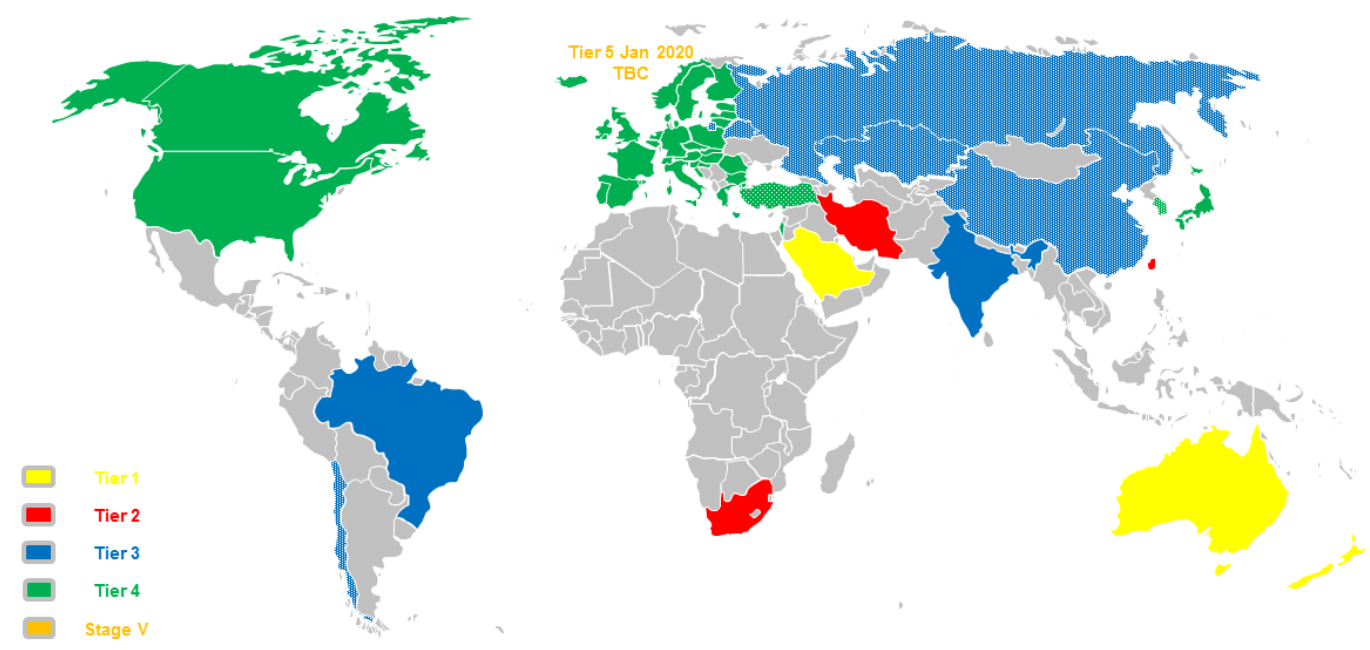

Figura 6: O Brasil em comparação com os demais mercados (aplicações fora-de-estrada)

\section{DESENVOLVIMENTO DOS MOTORES MAR-I}

De maneira geral, considera-se que, para o cumprimento da regulamentação MAR-I para motores off-road algumas modificações mecânicas nos motores base são necessárias. Tais soluções, como descritas na tabela 2, preconizam estabelecer duas estratégias distintas: (A) Aumento da eficiência de combustão para posterior redução do NOx ou (B) Redução da temperatura de combustão para posterior tratamento dos gases para redução de Material Particulado.

\begin{tabular}{|l|l|c|}
\hline \multicolumn{1}{|c|}{ Tecnologia } & \multicolumn{1}{c|}{ Objetivo } & $\begin{array}{c}\text { Estratégia } \\
\text { para MAR-I }\end{array}$ \\
\hline Turbina com maior eficiência & $\begin{array}{l}\text { Aumentar a disponibilidade de ar em } \\
\text { condições transientes }\end{array}$ & A ou B \\
\hline $\begin{array}{l}\text { Sistema de Recirculação dos Gases } \\
\text { (EGR) }\end{array}$ & $\begin{array}{l}\text { Recircular os gases de escape para } \\
\text { resfriar a temperatura da combustão }\end{array}$ & $\mathrm{B}$ \\
\hline Mudança do mapa de calibração & Aumento da eficiência da combustão & $\mathrm{A}$ \\
\hline $\begin{array}{l}\text { Novo sistema de Injeção (bomba de } \\
\text { combustível + bicos injetores) }\end{array}$ & $\begin{array}{l}\text { Aumento da eficiência e maior } \\
\text { controle da combustão }\end{array}$ & $\mathrm{A}$ \\
\hline Novos eixos comando de válvula & $\begin{array}{l}\text { Promover a recirculação interna dos } \\
\text { gases }\end{array}$ & $\mathrm{B}$ \\
\hline $\begin{array}{l}\text { Novas Centrais Eletrônicas com } \\
\text { maior capacidade de processamento e } \\
\text { adoção de novos sensores }\end{array}$ & $\begin{array}{l}\text { Promover o maior controle da } \\
\text { combustão }\end{array}$ \\
\hline
\end{tabular}

Tabela 2: Tecnologias desenvolvidas para atendimento do PROCONVE MAR-I

A Estratégia definida varia de acordo com cada motor, sendo possível a utilização de uma ou mais tecnologias, de acordo com a demanda necessária para o cumprimento da regulamentação MAR-I.

\subsection{MOTORES COM EGR REFRIGERADO}

Através da recirculação controlada de parte dos gases de escape para o interior da câmara, ocorre a redução da concentração de Oxigênio pela inserção de gases triatômicos inertes, 
como Dióxido de Carbono $\left(\mathrm{CO}_{2}\right)$. A redução controlada de Oxigênio causa a redução da temperatura de combustão e como consequência, ocorre a redução na emissão de Óxidos de Nitrogênio. Os gases de escape, ao deixarem a câmara de combustão, são direcionados para o trocador de calor - conhecido como EGR Cooler (Figura 7), sendo resfriados e retornando em seguida para a câmara de combustão. Com a redução de temperatura no interior da câmara, ocorre o aumento da emissão de Material Particulado, fenômeno conhecido como "trade-off", e por esse motivo todo o mapa de funcionamento do motor deve ser testado em dinamômetro para garantir que o motor atenda os limites de emissões. A recirculação de gases de escape é controlada em função do ponto de operação do motor, ou seja, em pontos de maior carga, a parcela de gases recirculados é menor, de modo a não impactar negativamente o funcionamento e resposta do motor, ao passo que nos pontos de baixa carga, ocorre a entrada de uma massa maior de gases.

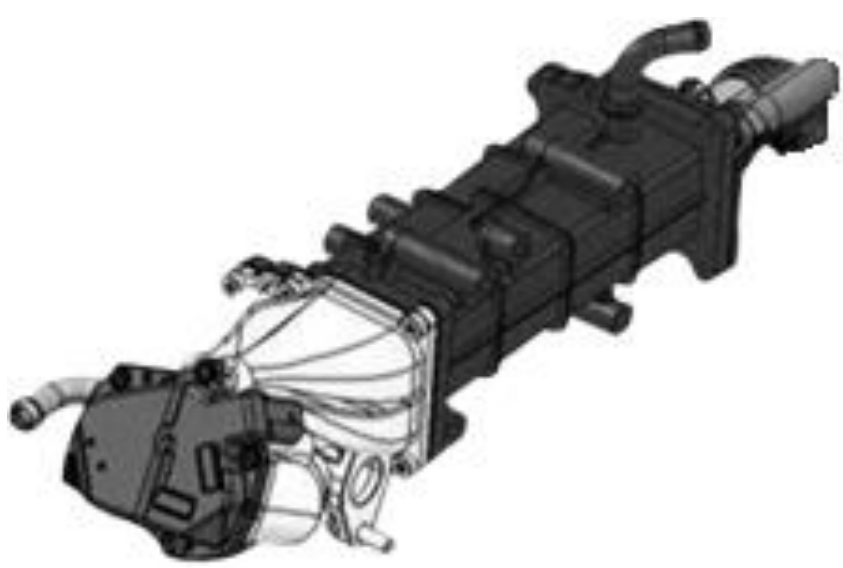

Figura 7: Exemplo de trocador de calor para os gases de escape (EGR Cooler)

Emissões brutas

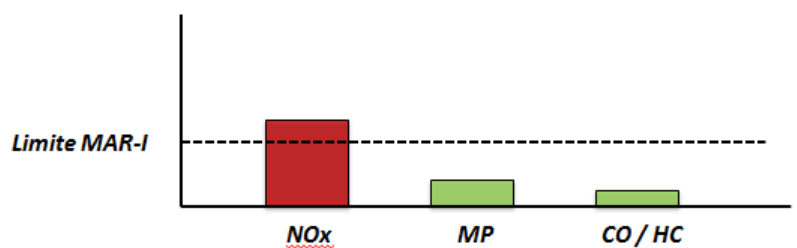

Utilização de EGR

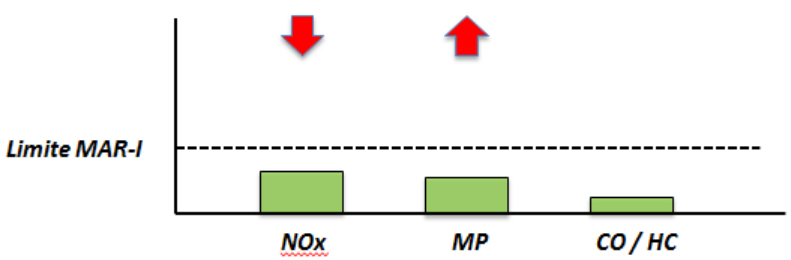

Figura 8: Redução de NOx através da Recirculação de Gases de Escape (EGR) 


\subsection{MOTORES COM EGR INTERNO}

Nos motores com EGR interno, uma parcela dos gases de escape é retornada para o coletor de admissão (A), através de abertura adicional da válvula de admissão durante o tempo de exaustão (nos motores sem EGR interno, as válvulas de admissão permanecem fechadas durante esse tempo).

A massa de gás inerte presente no coletor de admissão é absorvida novamente pelo mesmo cilindro ou por qualquer outro que esteja no tempo de admissão, ocupando parte do volume do cilindro e diminuindo assim o volume de Oxigênio. Com uma presença menor desse gás, a combustão ocorre com temperaturas mais baixas, controlando a emissão de NOx.

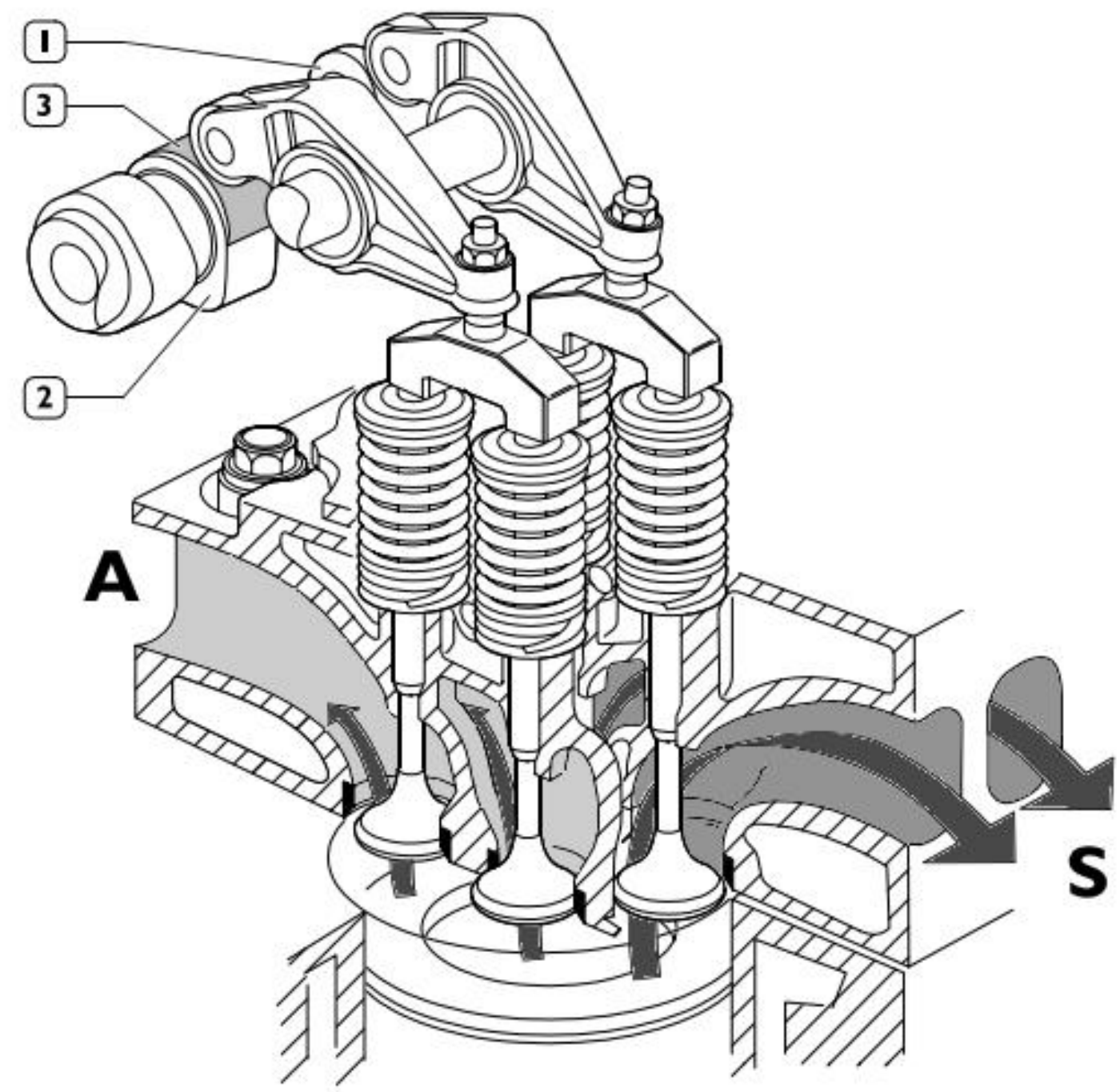

Figura 9: Recirculação Interna de gases de escape 


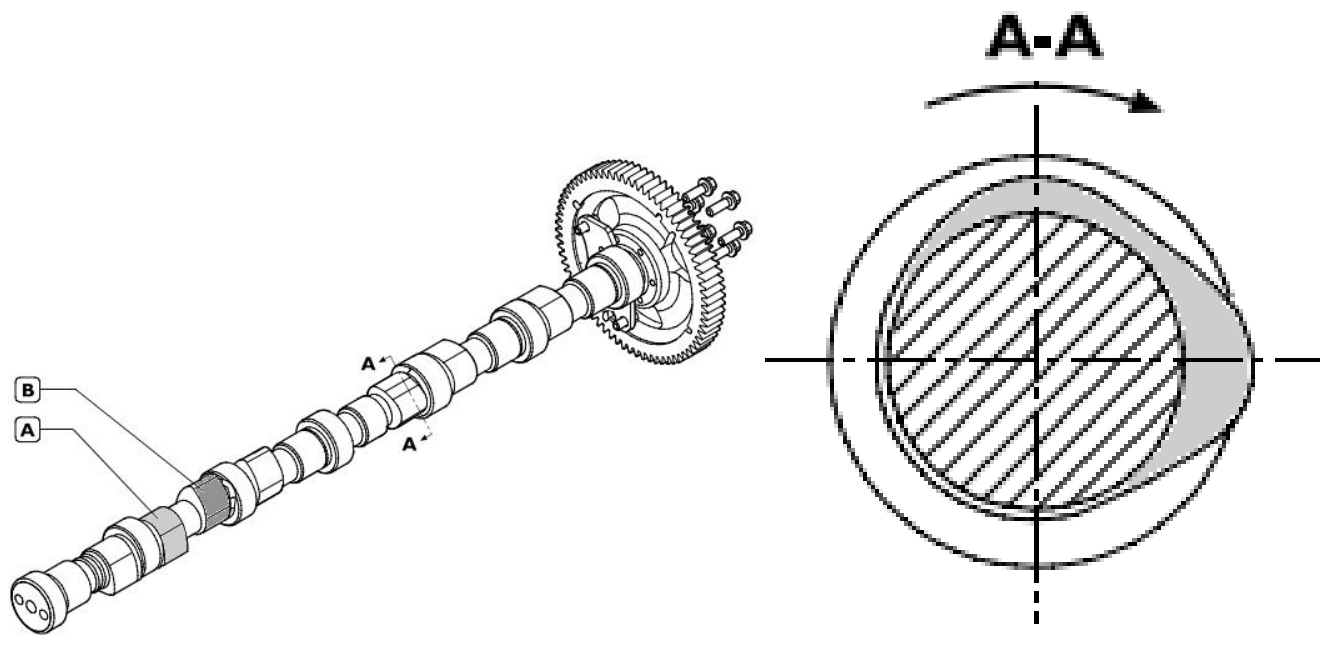

Figura 10: Eixo de comando de válvulas com came adicional para a válvula de admissão

\subsection{MOTORES COM SCR}

O motor equipado com a tecnologia SCR (Redução Catalítica Seletiva) é desenvolvido para operar com a máxima eficiência, de modo que a emissão de Monóxido de Carbono, Hidrocarbonetos e Material Particulado seja minimizada. Em contrapartida, a emissão de Óxidos de Nitrogênio atinge valores brutos elevados, porém, com o compromisso de que seja, em seguida, tratada no catalisador.

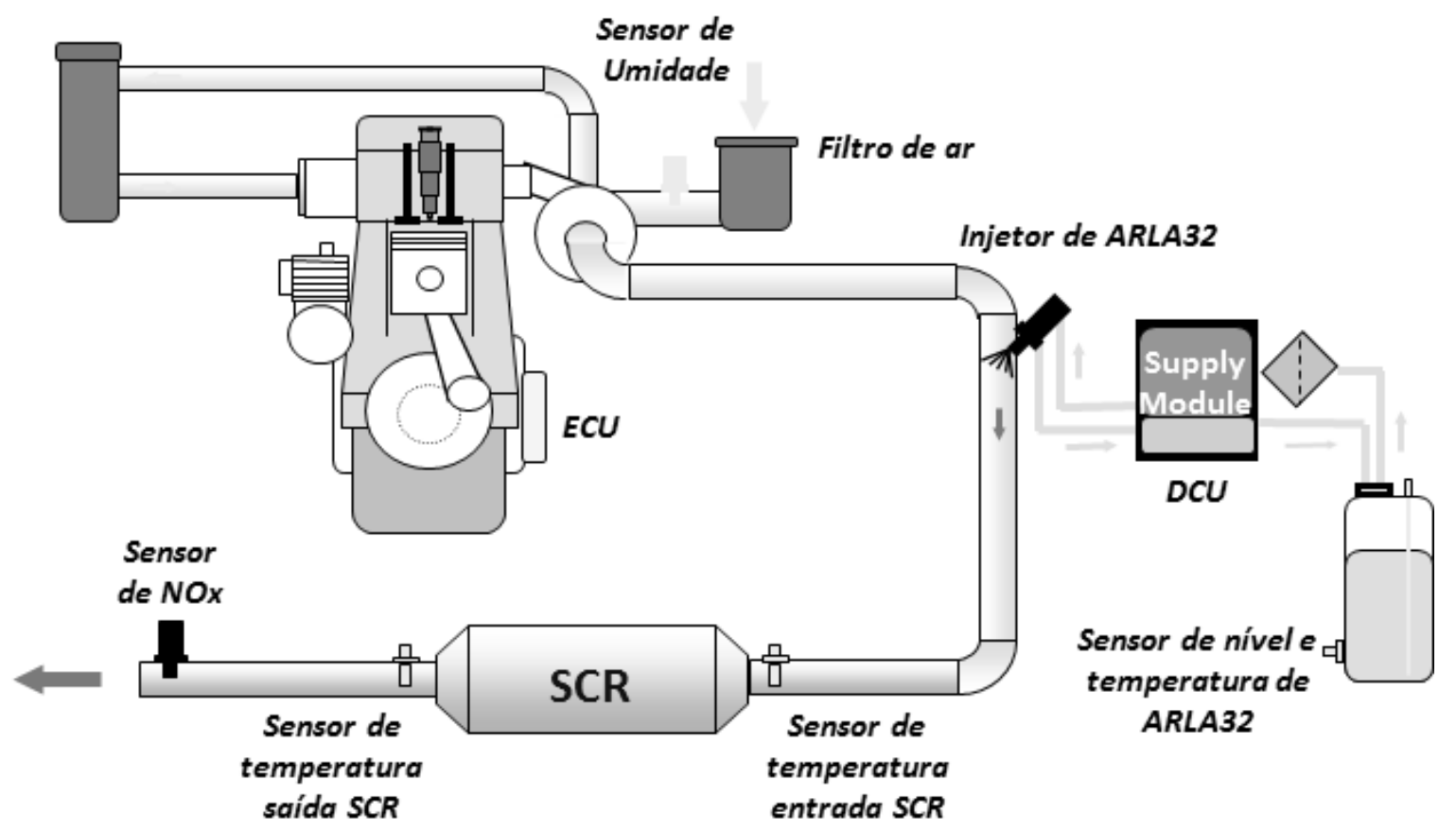

Figura 11: Componentes do sistema SCR

O sensor de NOx efetua a leitura dos valores de Óxidos de Nitrogênio e envia a informação para a ECU do motor, que através de um mapa com todos os pontos de operação, interpreta os valores de emissões, identificando se o poluente está em conformidade com os valores admissíveis ou se precisarão ser tratados. 
A ECU recebe informações de temperatura na entrada e saída do catalisador através dos respectivos sensores. Se a temperatura estiver acima de $200^{\circ} \mathrm{C}$, um sinal é enviado pela ECU à DCU (Módulo Eletrônico de suprimento de ARLA32). A DCU calcula a quantidade de ARLA32 necessária ao abatimento do NOx, succionando o fluido diretamente do tanque através das mangueiras e envia ao injetor de ARLA32 (Agente Redutor Líquido Automotivo).

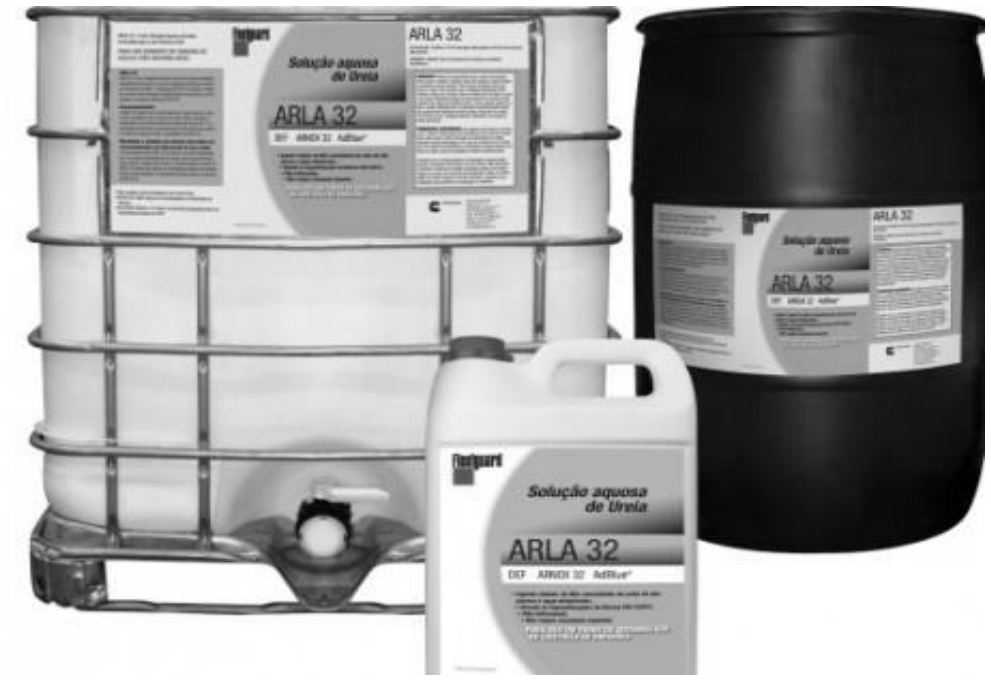

Figura 12: Embalagens de ARLA32

O injetor, posicionado no tubo de escape do trator ou máquina, injeta o ARLA32, que é pulverizado e misturado aos gases de escape. Ocorre neste momento a reação denominada Termólise, com transformação de parte do ARLA32 em $\mathrm{NH}_{3}$.

Ao entrar no catalisador à base de Vanádio, em temperatura superior a $200^{\circ} \mathrm{C}$, o restante do ARLA32 é definitivamente transformado em $\mathrm{NH}_{3}$ através da reação denominada Hidrólise. A partir daí, os gases de escape são tratados pelo $\mathrm{NH}_{3}$, e são emitidos à Atmosfera $\mathrm{N}_{2}$ e Água, elementos que não causam qualquer mal à saúde humana.

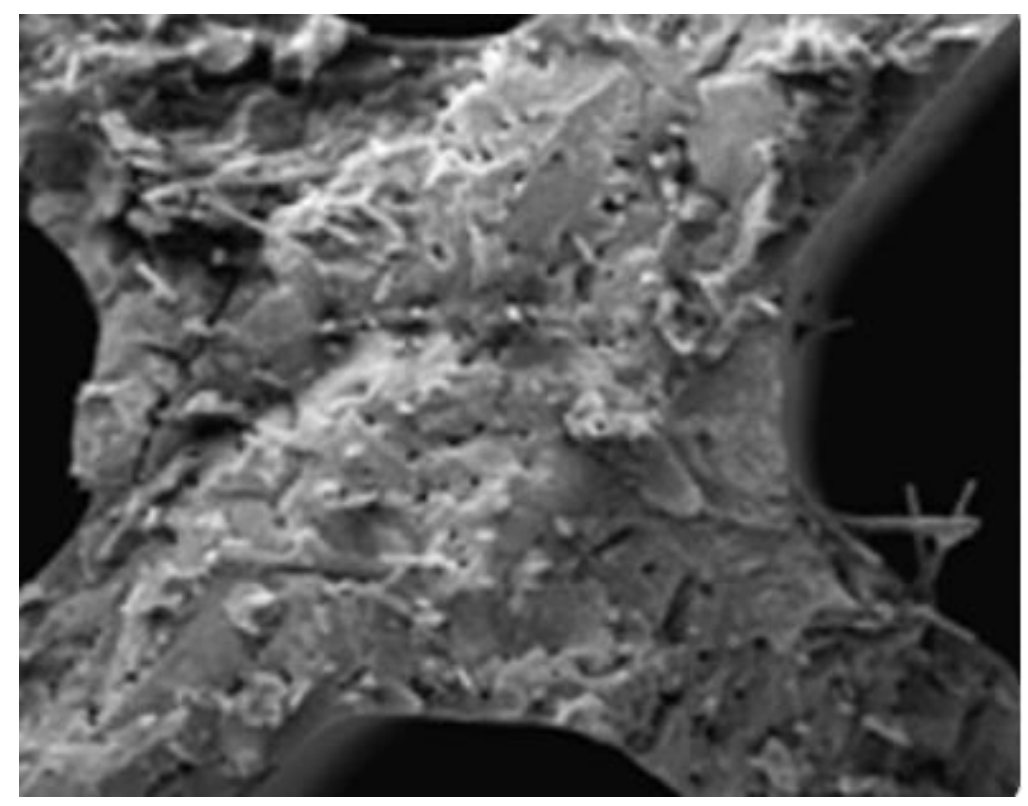

Figura 13: Catalisador à base de Vanádio 


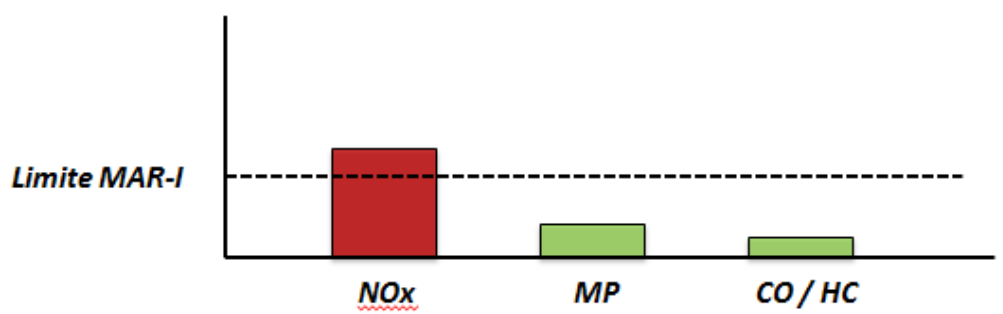

Otimização da combustão

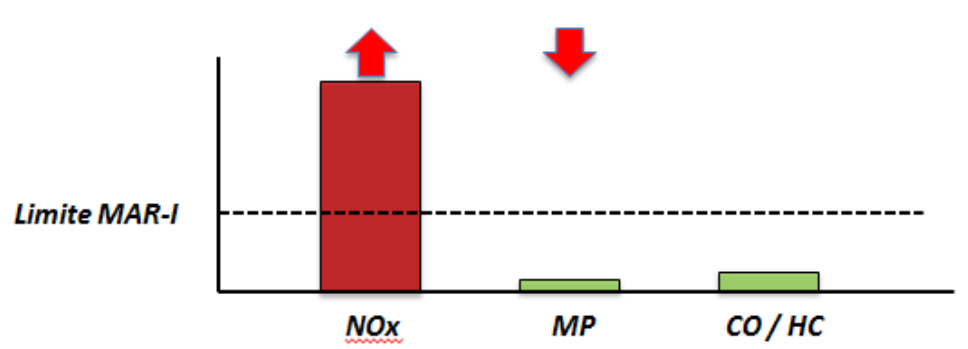

Utilização de SCR

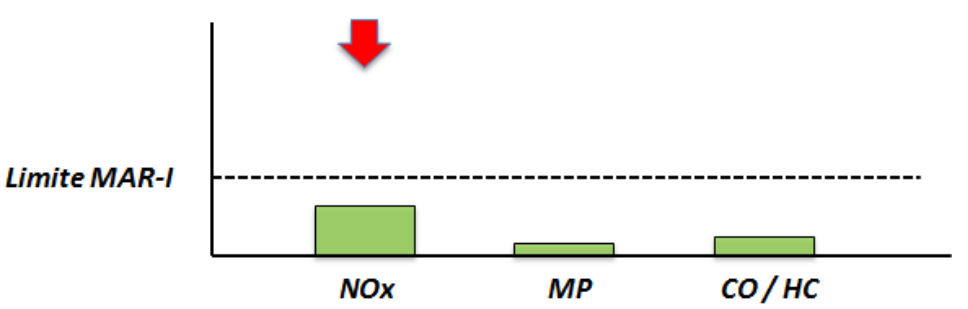

Figura 13: Redução de NOx através de SCR

A partir do momento em que o sensor detecta que as emissões de NOx estão em conformidade com os parâmetros pré-estabelecidos, DCU recebe sinal para reduzir a injeção de ARLA32. Esse controle é chamado de "close loop", que ocorre milhares de vezes por minuto.

ARLA32 é bombeado continuamente para garantir a refrigeração do injetor, exposto às altas temperaturas dos gases de escape. Aquela parcela não injetada retorna para o tanque. 
Se a temperatura do catalisador for inferior a $200^{\circ} \mathrm{C}$, não há a injeção de ARLA32, pois as reações de termólise e hidrólise de ureia ocorrem acima deste valor, e o fluido injetado não proporcionaria qualquer redução das emissões de NOx.

\section{VALIDAÇÃO}

Para o atingimento dos limites de emissões propostos no MAR-I, foi desenvolvido um vasto programa de desenvolvimento e validação das máquinas agrícolas e de construção (em execução desde 2015 e com término previsto em 2017) dependendo do tipo de aplicação da máquina. Esse programa envolve, além do desenvolvimento das novas tecnologias, a validação das soluções propostas e testes em bancada e durabilidade no campo. O programa abrange mais de 50 máquinas em campo e 20 mil horas de validação, incluindo os testes de bancada.

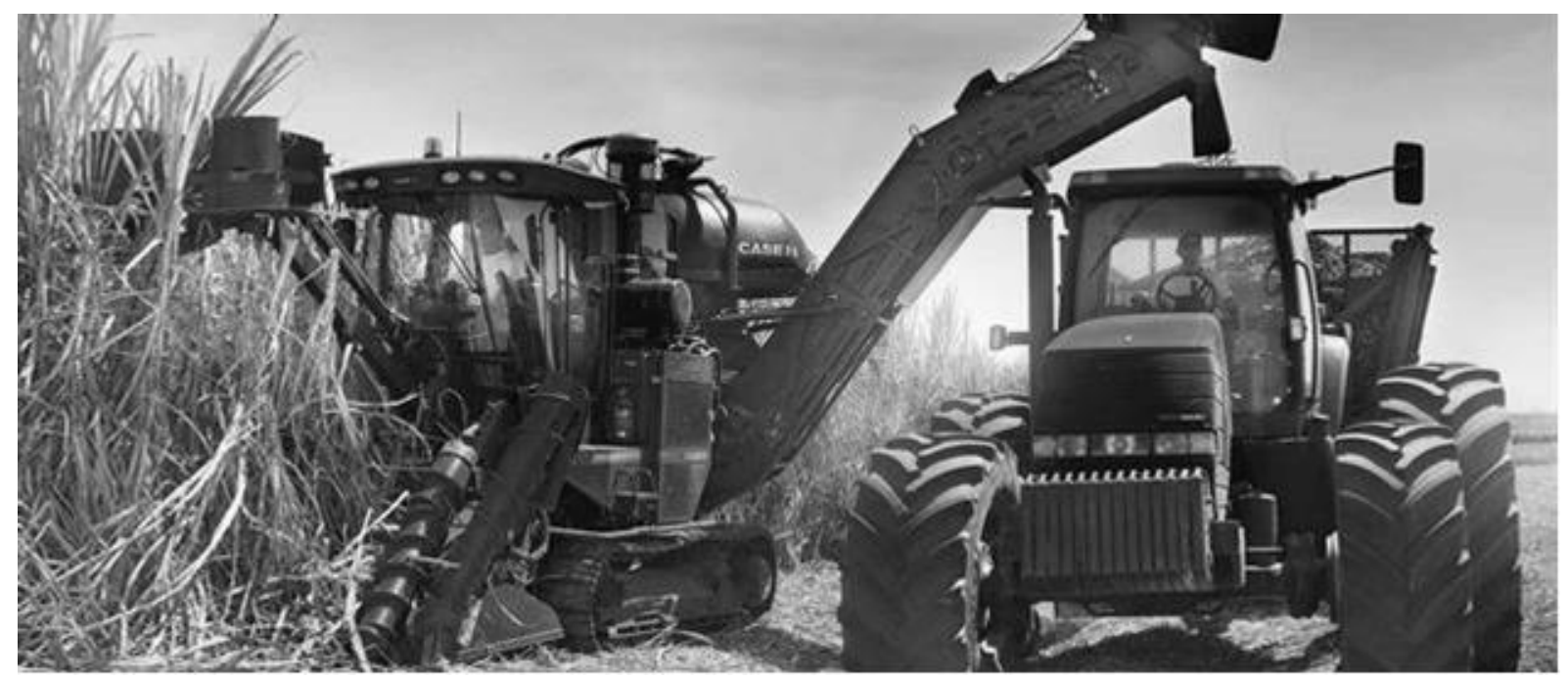

Figura 14: Trator e colhedora de cana em teste de validação em campo

\section{HOMOLOGAÇÃO DE MOTORES}

A homologação dos motores FPT para atender os limites MAR-I nas aplicações de construção e agrícolas totaliza 49 diferentes versões, trazendo para o time de funcionários a possibilidade de aprendizado através de diversos desafios, internos e externos.

A homologação de um motor é uma atividade intrínseca à rotina de um fabricante de motores, envolvendo membros dos mais diferentes setores, como desenvolvimento de motores, calibração, aplicação, validação, sistemas de pós-tratamento, metrologia, protótipos, entre outros, como logística, transporte, fiscal e integração com o cliente.

As diferentes plataformas internas têm as suas demandas próprias (diretamente ligadas aos prazos e necessidades dos clientes) e devido a isso, diferentes prioridades. 
Os motores são fabricados em diferentes plantas produtivas e por esse motivo, estão sujeitos a diferentes prazos de chegada e preparação para ensaio.

Todos os motores devem ser testados de acordo com o ciclo NBR ISO 8178, conhecido como ciclo de 8 pontos (Figura 15), no qual deve ser utilizado o combustível padrão S-300 (300 ppm de Enxofre).

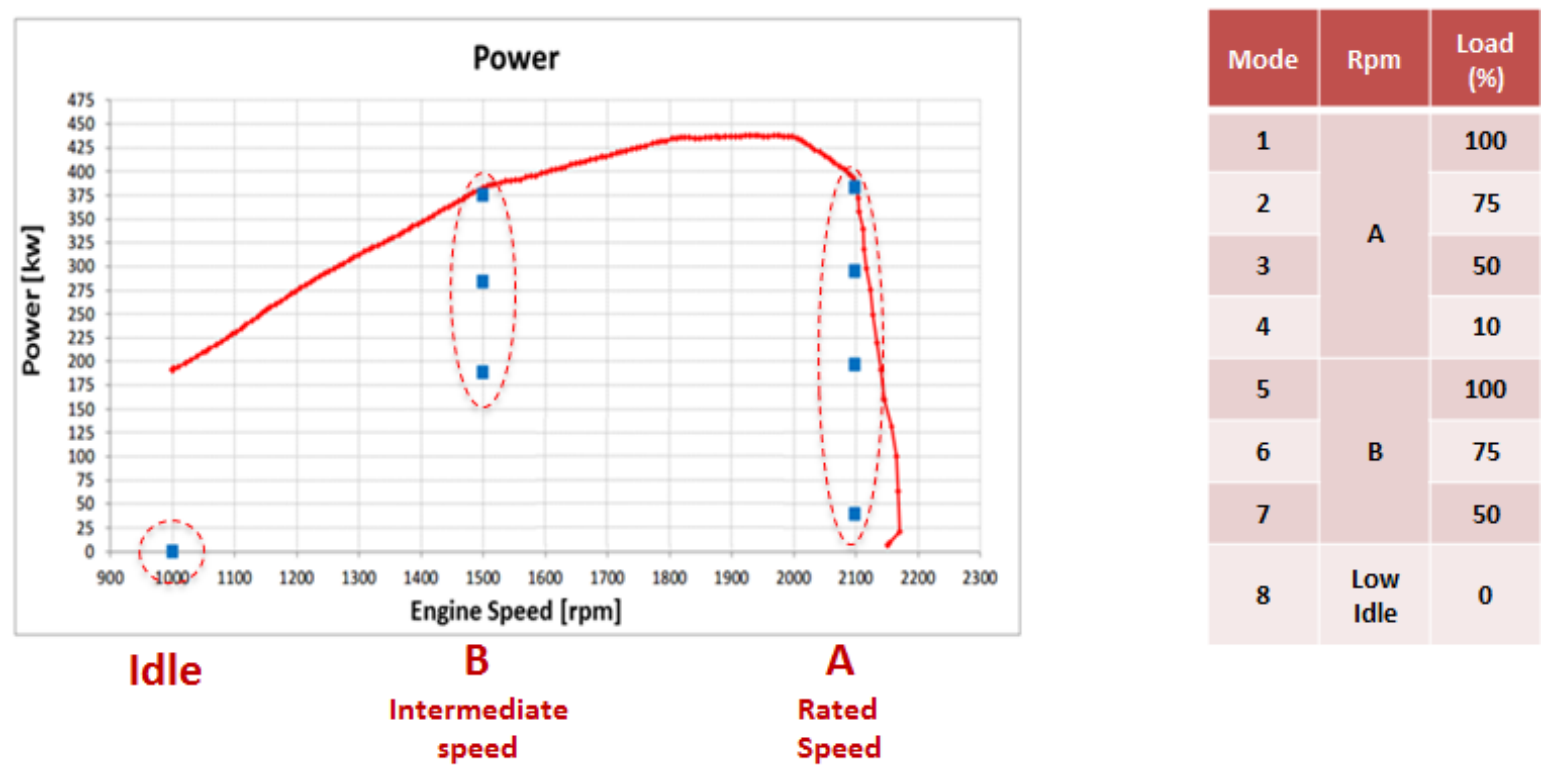

Figura 15: Ciclo de testes ISO 8178
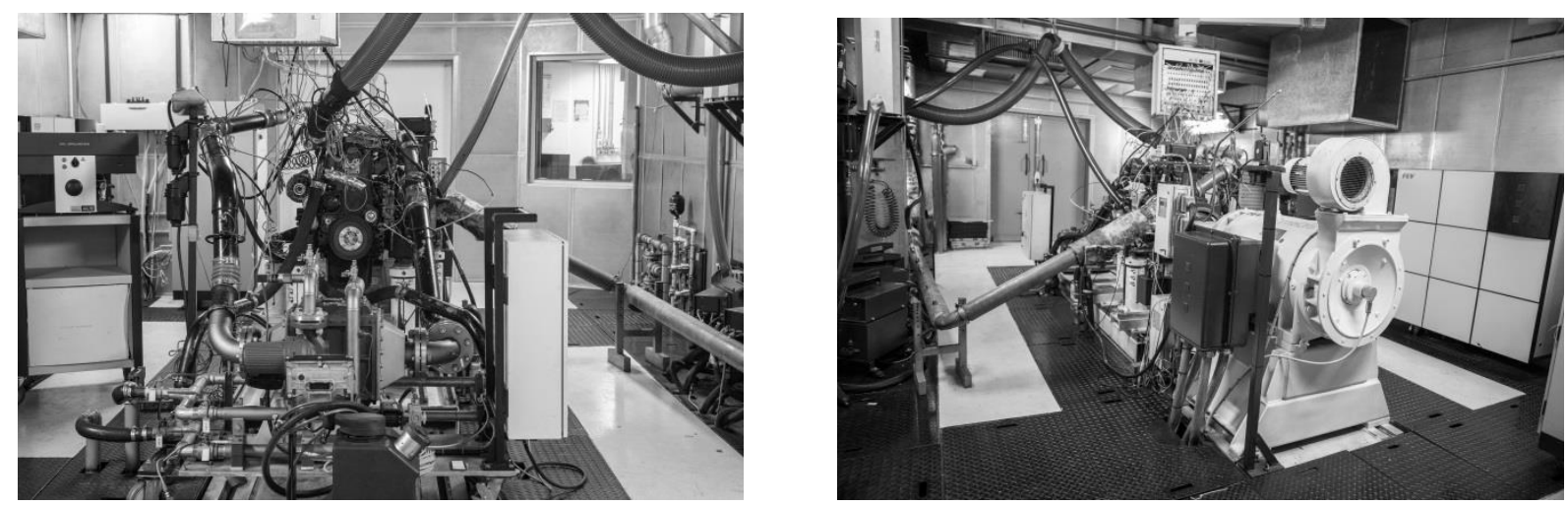

Figura 16: Motor no banco de testes durante realização do ciclo ISO 8178

No início das discussões sobre MAR-I com os órgãos governamentais, foi feita pelos fabricantes de motores e máquinas uma previsão de consumo de combustível para que a Petrobrás preparasse uma batelada especial para atendimento aos fabricantes de motores. Discussões envolvendo Petrobrás e ANP se desenrolaram por diversos meses, devido à necessidade de autorização de produção, etc., o que gerou grande atraso no início das atividades.

À parte todas as dificuldades mencionadas, o maior desafio foi a criação de um calendário de homologações que levasse em consideração todos esses pontos. Houve a necessidade de criação de um calendário dinâmico, revisado semanalmente, prevendo atrasos, novas 
demandas, mudanças de prioridades, agendas de órgãos certificadores e agentes técnicos credenciados (CETESB).

As reuniões para revisão do calendário envolvem diversos engenheiros, representando diferentes setores. Diversos mecanismos foram implementados para aumentar a confiabilidade de dados. Os dados são revisados por todos e podem ser facilmente acessados por toda a equipe.

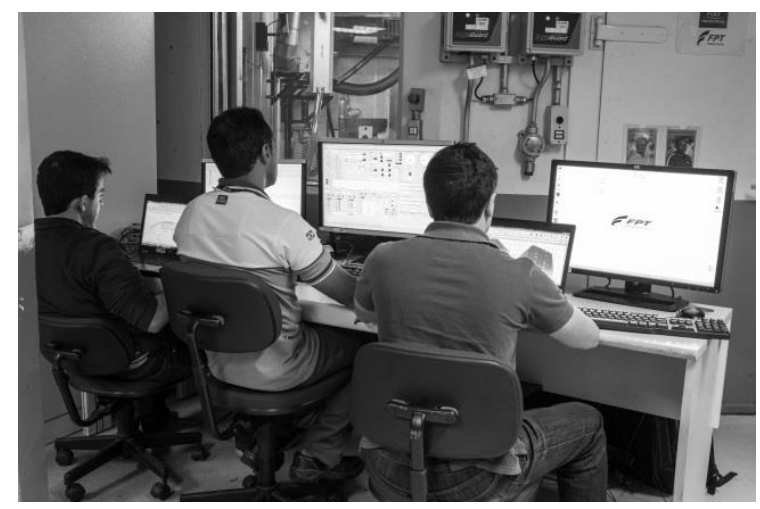

Figura 17: Equipe de Engenheiros realizando ciclo ISO 8178 em dinamômetro

\section{RESULTADOS OBTIDOS}

Considerando as emissões de todos os motores homologados até Maio/2016 e seus respectivos volumes anuais de vendas, em comparação com os motores anteriores (não emissionados), cerca de 950 toneladas de Material Particulado deixaram de ser emitidas para a atmosfera anualmente, assim como cerca de 12.000 toneladas de Óxidos de Nitrogênio.

Isso corresponde a 3,6 kg de Material Particulado que deixam de ser emitidos para a atmosfera, ou 46,4 kg de Óxidos de Nitrogênio a cada minuto.

\section{Redução de Material Particulado (ton)}

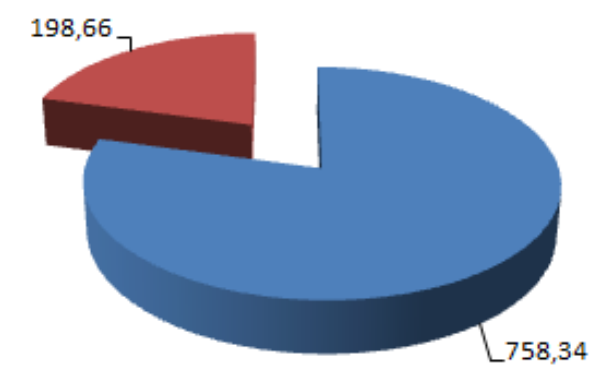

- Tratores e máquinas agrícolas

Equipamentos de construção

Figura 18 : Redução da emissão de Material Particulado em motores fora-de-estrada 


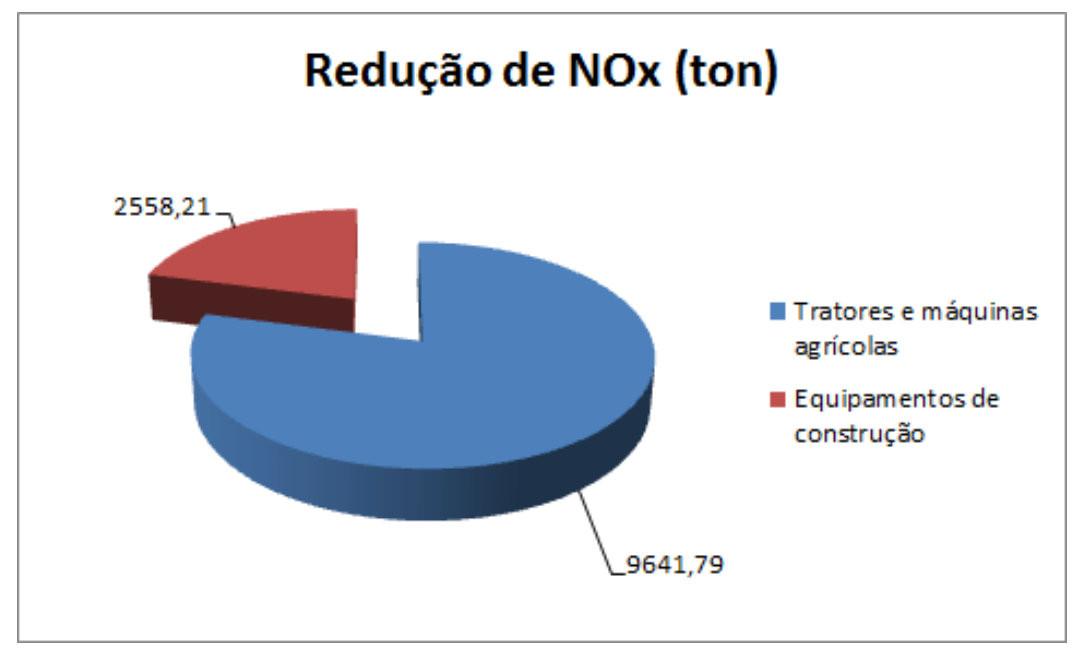

Figura 19: Redução da emissão de Óxidos de Nitrogênio em motores fora-de-estrada

\section{CONCLUSÃO}

Através do desenvolvimento e homologação de novas versões de motores, a FPT Industrial avançou fortemente em seu calendário proposto de homologações de tratores e máquinas de construção, com cerca de $60 \%$ dos motores homologados até Maio/2016.

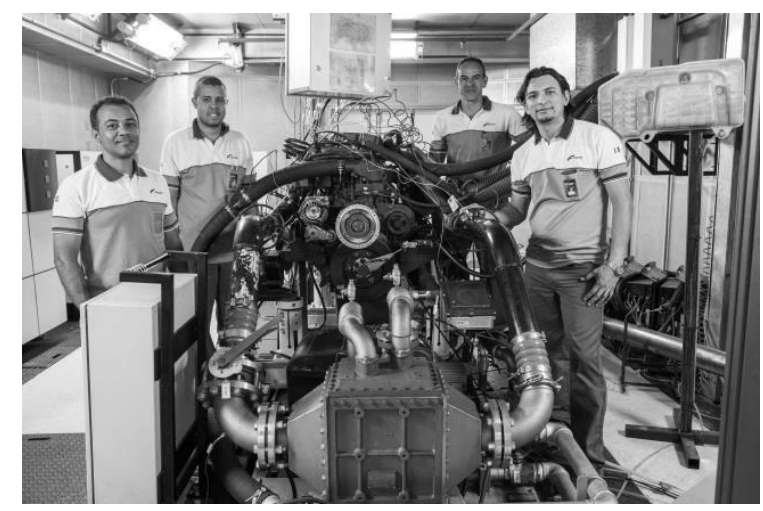

Figura 20: Equipe durante homologação do motor no dinamômetro

Tudo isso somente vem sendo possível com a integração e participação de toda a equipe, trazendo grandes benefícios para a sociedade e o meio-ambiente, uma vez que cerca de 13.000 toneladas de poluentes deixam de ser emitidas para a atmosfera anualmente. 


\section{REFERÊNCIAS}

[1] MOLLENHAUER, Klaus; TSCHOEKE, Helmut. Bosch Handbook of Diesel Engines: Springer, 2010.

[2] RESOLUÇÃO CONAMA 433. Diário Oficial da União no. 134, pág. 69, 14/07/2011.

[3] NBR ISO 8178, Motores alternativos de combustão interna - Medição da emissão de gases de exaustão. Parte 1: Medição das emissões de gases e material particulado em banco de ensaio.

[4] RESOLUÇÃO ANP No. 71. Diário Oficial Da União, 22/12/2011 